\title{
TULEVIKU TULEKUST: \\ TULEVIKULISUSE VÄLJENDAMISEST MEIE ESIMESTES PIIBLITÕLGETES ${ }^{1}$
}

\author{
Annika Kilgi \\ Tallinna Ülikool
}

Kokkuvõte. Eesti keelde Piiblit tõlkima hakates tuli otsustada, kuidas anda lähteteksti rohkeid tulevikuvorme edasi maakeeles, milles puudus morfoloogiline futuurum. Teekonnal esimese täispiiblini tehti selles osas põhimõtteliselt erinevaid otsuseid. 17. sajandi algul Georg Müller oma jutlustes saama-tulevikku ei kasutanud, 1630.-1680. aastate piibliversioonides aga anti tulevikusündmusi edasi peamiselt just selle saksa werden-futuurumi eeskujulise konstruktsiooniga. 17. sajandi lõpus, Müncheni käsikirjast alates loobuti taas saama-futuurumist täiesti ning kasutati tuleviku vahendamiseks senisest märksa rohkem hoopis pidamatarindeid ja kindla kõneviisi olevikuvorme. Põhimõttelise muudatusena paistab silma veel konstruktsiooni võtma $+d a$-infinitiiv varasemast sagedasem kasutus redaktsioonides, mida toimetasid 1720.-1730. aastatel täispiibli keelele lõpliku kuju andnud pietistid. Neutraalse tähendusega puhast tulevikutarindit ei õnnestunud siiski ühelgi tõlkijal leida. Saama-tuleviku massiline kasutus oli võõrapärane, ülejäänud väljendusviiside (nt pidama-, tahtma-, hakkama-, algama- ja võtma-konstruktsiooni) tarvitusala jällegi liiga lai. See, et pidama-tarindiga tõlgiti alates Müncheni käsikirjast ka paljusid lähtekeeles modaalvarjundita tulevikuvorme, on võrreldav varasema saama-konstruktsiooniga liialdamisega.

Märksõnad: tulevikulisuse väljendamine, futuurum, saamatarind, pidama-tarind, eesti piiblitõlke ajalugu, Luuka evangeelium, 17. sajand, 18. sajand

${ }^{1}$ Olen tänulik Kristiina Rossile ja Külli Habichtile, kes jagasid lahkelt enda valduses olevaid Uue Testamendi redaktsioonide sisestusi. Ilma nendeta oleks see artikkel ilmunud Helle Metslangi 65. juubeliks. Rohkesti tänu võlgnen retsensendile, kelle märkused kirjutise tunduvalt sisukamaks ja loetavamaks muutsid. 


\section{Sissejuhatus}

Võib arvata, et esimesed piiblitõlked panid eestlasi tulevikule mõtlema hoopis rohkem ja teisiti kui varem. Igavese elu tõotus ja paljud muud pühakirjas olevad ettekuulutused suunavad paratamatult mõtlema eesootavale. Kuidas tulevikuideed aga vormiliselt väljendada, polnud eesti kirjakeele algusaegadel sugugi selge. Piiblitekstis, mida võoorkeeltest vahendama hakati, esines rohkesti futuurumit, eesti verbil aga taolist vormi polnud ning tuli otsustada, milliseid keelevahendeid selle asemel kasutada. Helle Metslangi sõnutsi hakati just usutekstide tõlkimise käigus esmakordselt otsima väljapääsu eesti keele futuurumipuudusest: „Võib oletada, et kuni keel pole omandanud kirjakeele funktsioone, vaid toimib kirjaoskamatu rahva argikeelena, seni võib tulevikuviite jaoks piisata suulise kõne liiasusestki. Grammatilise tulevikuaja puudumine muutus nii eesti kui ka soome keele puhul häirivaks kirjakeele kujunemisel, seda hakkas vaja minema religioossete tekstide tõlkimisel" (Metslang 1994: 540).

Siinne artikkel ongi pühendatud tulevikulisuse väljendamise püüdlustele eesti kirjakeele algusaegadel: esimestest säilinud piiblitõlkeridadest kuni esimese täispiiblini. Täpsemalt on vaatluse all Luuka evangeelium seitsmeteistkümnes tõlkeversioonis, ${ }^{2}$ mille loend on artikli lisas. Sinna on märgitud ka tõlgetes leidunud öeldiste koguarv, kuna tekstid olid mahult väga erinevad: ainult kuus Luuka evangeeliumi tõlget on säilinud tervikuna; Gutslaffi tõlkest ning Pilistvere käsikirjast on osa peatükke puu$\mathrm{du}$; kirikuraamatud sisaldavad ainult jutluse aluseks olevaid kirjakohti; Mülleri jutlustest õnnestus leida vaid mõni Luuka evangeeliumi tsitaat. Kõrvutan neid 17 Luuka evangeeliumi eestindust kolme tekstiga, mis on paljude Uue Testamendi (edaspidi UT) tõlgete kõige olulisemateks taustsüsteemideks rahvakeele kõrval: 1) kreekakeelse originaaliga (millest kasutan varianti

${ }^{2}$ Ajapuudusel jäi kahjuks võrdlusest välja Joachim Balecke Luuka evangeeliumi käsikiri, mis valmis juba 1684. aastal, kuid mille asemel asuti 1687. a Pilistvere piiblikonverentsil millegipärast tööle hoopis ebaühtlase ja pooliku käsikirja kallal (Tafenau 2006: 274), samuti Heinrich Göseken vanema käsikiri, millest lähtusid oma evangeeliumitõlgetes vähemalt Balecke ja Heinrich Göseken noorem (Tafenau 2010: 196). 
Textus Receptus, käesolevas artiklis lühendatud kr-TR); 2) katoliku mõjupiirkondades ja -aegadel valitsenud ladina tõlke Vulgataga (ld-V) ning 3) hiljem luterluse levialal sarnase autoriteedi saavutanud Martin Lutheri piiblitõlkega (sks-L). Analüüsin, kuidas anti varastes eesti tõlgetes edasi salme, kus vähemalt üks nimetatud kolmest mõjukast piibliversioonist kasutas spetsiaalset tulevikuvormi või -tarindit. Kokku oli taolisi kohti, kus vähemasti üks kolmest piibliversioonist kasutas taolist puhast tulevikku väljendavat keelendit, 395. Arvestamata jätsin selliste tulevikusündmustest rääkivate lausete tõlked, milles kõik need kolm kasutasid oleviku- või minevikuvormi, leksikaalseid vahendeid ning modaalseid ja algust väljendavaid konstruktsioone, mille puhul tulevikule viitamine oli vaid üks funktsioon teiste seas. Keelenäited, mis illustreerivad levinumaid tuleviku tõlkimise viise, leiab alaosast 4. Võrdluseks on seal lisatud sama kirjakoha alternatiivne tõlge ning kr-TR, ld-V ja sks-L tekst.

\section{Tuleviku tõlkimise taust}

\subsection{Tuleviku väljendamine lähtekeeles}

Kreeka, ladina ja saksa keele mitmesuguste tulevikule viitamise võimaluste sekka kuuluvad spetsiaalsed verbivormid. Lisaks n-ö tavalisele futuurumile on olemas ka lõpetatust väljendavad vormid, nt ladina keeles peale esimese futuurumi audiam 'ma kuulan (tulevikus)' ka teine futuurum audivero 'ma olen kuulanud (tulevikus)'.

Luuka evangeeliumis on 186 öeldist, mille puhul nii kr-TR, ld-V kui ka sks-L kasutavad indikatiivi futuurumit. Lisaks leidub 209 juhtumit, mille puhul tulevikuvormis öeldis esineb ainult ühes või kahes piibliversioonis kolmest ning mujal kasutatakse morfoloogilise futuurumi asemel peamiselt algust väljendavaid tarindeid ning modaalvorme ja -ühendeid.

Neis 209 kirjakohas, kus kõik kolm vaadeldud UT versiooni ei tarvita üksmeelselt indikatiivi futuurumit, rakendab kr-TR järgnevaid vormistusviise: indikatiivi futuurum (98), konjunktiivi esimene aorist (21), konjunktiivi teine aorist (17), preesensi 
partitsiip (11), indikatiivi preesens (16), indikatiivi teine futuurum (7), 'alustama'-tarindi 'ö $\rho \chi \rho \alpha l+$ infinitiiv' konjunktiiv (6), imperatiivi preesens (4), aoristi partitsiip (4), teise aoristi partitsiip (3), 'pidama'-tarind ' $\mu \dot{c} \lambda \lambda \omega+$ infinitiiv' (3), preesensi infinitiiv (3), 'pidama'-tarind ' $\delta \varepsilon \tilde{\imath}+$ infinitiiv' (2), 'võima'-tarindi

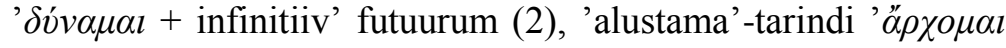
+ infinitiiv' futuurum (2), aoristi infinitiiv (2), noomenivorm (2), konjunktiivi preesens (1), teise aoristi infinitiiv (1), indikatiivi aorist (1); võrreldav vorm puudus 3 juhul.

Ld-V tekstis on nende 209 koha tõlkimisel kasutatud alljärgnevaid vormivahendeid: indikatiivi futuurum (109), indikatiivi preesens (22), indikatiivi teine futuurum (21), konjunktiivi preesens (17), preesensi partitsiip (9), konjunktiivi imperfekt (7), 'alustama'-tarindi 'coepio + infinitiiv' teine futuurum (4), 'alustama'-tarindi 'incipio + infinitiiv' teine futuurum (4), 'võima'tarindi 'possum + infinitiiv' futuurum (3), 'vaja olema'-tarind 'oportet + infinitiiv' (3), imperatiivi futuurum (3), imperatiivi preesens (2), futuurumi partitsiip (1), noomenivorm (1); võrreldav vorm puudus 3 juhul.

Sks-L tõlkis neid kohti nõnda: indikatiivi futuurum (68), 'pidama'-tarindi 'sollen + infinitiiv' preesens (44), indikatiivi preesens (28), 'tahtma'-tarindi 'wollen + infinitiiv' preesens (27), 'pidama'-tarindi 'sollen + infinitiiv' futuurum (11), teise konjunktiivi futuurum (9), 'pidama'-tarindi 'müssen + infinitiiv' esimese konjunktiivi preesens (8), konjunktiivi preesens (3), 'pidama'-tarindi 'müssen + infinitiiv' futuurum (2), imperatiivi preesens (2), 'alustama'-tarindi 'anfangen $z u+$ infinitiiv' futuurum (2), 'alustama'-tarindi 'anfangen $z u+$ infinitiiv' preesens (2), 'pidama-võima'-tarind 'sollen können + infinitiiv' (1), 'võtma'-tarindi 'vornehmen $z u+$ infinitiiv' imperatiiv (1), indikatiivi perfekt (1).

\subsection{Tuleviku väljendamine sihtkeeles}

Ehkki tulevikuvorm puudub paljudes Euroopa keeltes (WALS 2005: 270), paistavad eesti ja soome keel ka nende hulgas silma sellega, et ei oma isegi perifrastilist järjekindlat tuleviku väljen- 
damise viisi (Dahl 1985), kuigi tulevikule muidugi mitmesuguste keelevahenditega viidatakse (Metslang 1994: 536). Arvata võib, et see valmistas raskusi ka neile, kes siin paar sajandit tagasi Piiblit tõlkida püüdsid.

Nende meeste arusaamu tuleviku väljendamisest eesti keeles peegeldavad tolleaegsed grammatikad, seda enam, et pühakirja tõlkimisega olid seotud kõigi viie enne täispiiblit ilmunud eesti keeleõpetuse autorid. Nende pilku eesti keele ehitusele mõjutasid nii kreeka, ladina kui ka saksa keel, mis polnud olulisel kohal mitte ainult Piibli tõlkeloos, vaid ka grammatikakirjutuse ajaloos: ${ }^{3}$ esimeste eesti keele kirjelduste autoriteks olid sakslased, kelle koostatud grammatikad esindasid tollases Euroopas üldlevinud ladina grammatikatraditsiooni, mille juured ulatuvad Antiik-Kreekasse. Seega pole üllatav, et sarnaselt eeskujukeeltega sisaldas tulevikuvorme ka esimestes eesti keele grammatikates esitatud verbivormistik.

Tuleviku abiverbiks oli esimeses kolmes eesti keele grammatikas saama, kuid soovimise ja võimalikkuse kõneviisis optatiivis lisasid Heinrich Stahl ja Johannes Gutslaff ka võima (Stahl 1637: 20 ja Gutslaff 1648: 146). Heinrich Gösekeni täiendused omakorda olid tahtma ja pidama (Göseken 1660: 37, 39). Kõigil neil on ilmsed (ülem)saksa eeskujud werden 'saama', können 'võima', wollen 'tahtma' ja sollen 'pidama', mis paistab kohe silma ka samade autorite kirjapandud usutekstide tõlkeid saksakeelsete lähteversioonidega kõrvutades.

Sellele, et maarahva kõnepruugis eeskujukeeltega võrreldav tulevik puudub, juhtis esimesena tähelepanu Johann Hornung, kelle sõnutsi kasutavad eestlased futuurumi asemel olevikuvorme, millele lisatakse mõnikord tulevikulisust väljendavaid sõnu tahan, küll või siis. Saama ei tundu talle tuleviku abiverbina mõistlik segaduse tõttu lausetega nagu Minna ei sa tänn tullema 'ma ei saa täna tulla' ning tulevikulises funktsioonis võivat verb esineda ainult mõnikord singulari kolmandas isikus, nt Jummal saab awwitama (Hornung 1693: 73).

${ }^{3}$ Eesti grammatikates leidub ka kõrvutusi heebrea keelega, näiteks Johannes Gutslaff reformis heebrea eeskujul käändevormistikku rektiivi kasutuselevõtuga (Gutslaff 1648: 46-48, 64-66) ja Eberhard Gutsleff tõi näiteid heebrea jälgedest eesti keeles (Gutsleff 1732: 14). 
Järgmises, Anton Thor Helle grammatikas puudus samuti Hornungi-eelsete grammatikate verbiparadigmasid läbinud konstruktsioon saama + infinitiiv, see-eest kuulus tema järgi tegusõna vormistikku tarind saama + mineviku kesksõna, mida ta nimetas konjunktiivi futuurumiks (Thor Helle 1732: 41). Sarnaselt Hornungiga loetles Thor Helle futuurumi (täpsemalt indikatiivi futuurumi) asendajatena preesensit ning sõna küll; sarnaselt eelmiste autoritega verbid pidama ja tahtma; omapoolse lisandusena sõnad küllap ja võtma (Thor Helle 1732: 32).

\section{Tulevik esimestes piiblitõlgetes}

Kõige suurem põhimõtteline otsus esimestest säilinud eesti keele ridadest kuni esimese täispiiblini puudutas saama-futuurumit. Ehkki 17. sajandi alguseks oli ülemsaksa keel omandanud juhtiva staatuse ning alamsaksa keel jäänud argikeeleks (Hennoste 1997: 51) ja ka Georg Müller eelistas oma 1600. aastatel kirja pandud jutlustes ülemsaksa keelt, väljendas ta tulevikulisust täiesti alamsaksapäraselt: alamsaksa willen- ja schöllen-tuleviku eeskujul kasutas Müller ka eesti keeles peamiselt tahtma- ja pidama-konstruktsioone. Heinrich Stahl seevastu väljendas oma 1630.-1640. aastate tekstides tulevikku juba ülemsaksa werdenfutuurumi eeskujulise saama-tarindiga. (Ross 1999: 12) Stahlipärane traditsioon püsis mitu aastakümmet, kuni Müncheni käsikirjani, mis on arvatavasti Johann Hornungi 1687/88 valminud tõlke ümberkirjutus 1694. aastast (Reila 2007). Tõlke tulevikukasutus vastab Hornungi grammatikas esitatud põhimõtetele: oli ju just tema oma grammatikast (1693) saama-futuurumi esmakordselt välja jätnud.

Müncheni käsikirjas loobuti saama-futuurumist täiesti ja asendati muude väljendusvahenditega. Enne Müncheni käsikirja (täpsemalt Luuka evangeeliumi versioonides Rossihnius 1632 EE 1693) kasutati tuleviku tõlkimiseks peamiselt saama-futuurumit (keskmiselt 5,42\% kõigist Luuka evangeeliumi öeldistest), vähem pidama-tarindit (keskmiselt 1,33\%), kindla kõneviisi olevikuvormi (keskmiselt 0,72\%), tahtma-tarindit (keskmiselt 0,49\%) ja muid vormistusviise. Müncheni käsikirjast alates jäeti 
aga saama-tulevik kõrvale ning asendati eelkõige pidama-tarindi ja kindla kõneviisi olevikuga, mille keskmine sagedus tõusis 4,26 ja 3,28 protsendini (vt joonist).

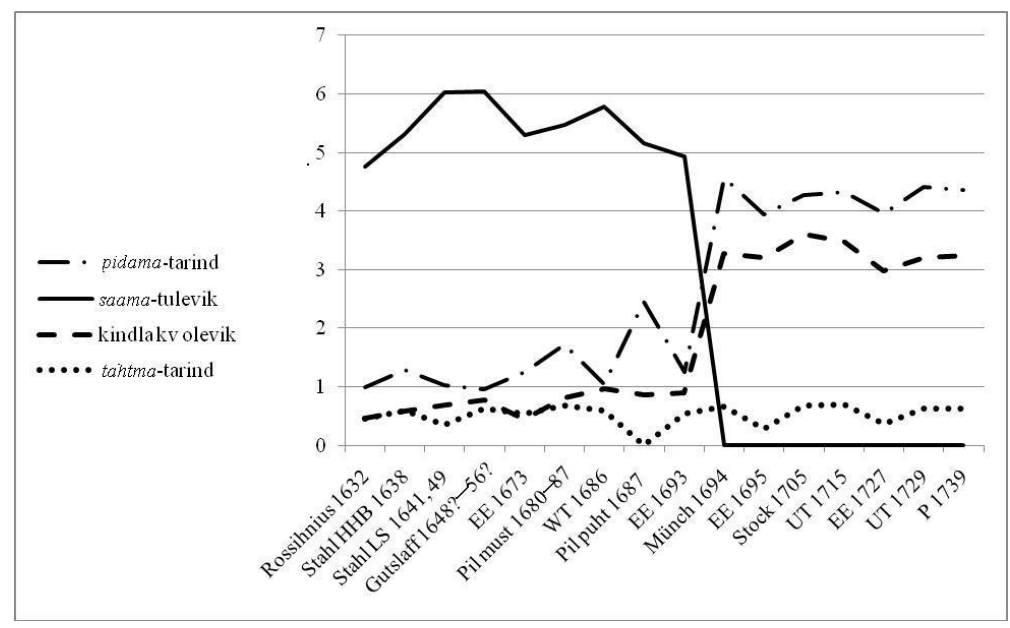

Joonis. Levinumate tuleviku väljendusviiside osakaal (protsentides) kõigist öeldistest esimestes Luuka evangeeliumi tõlgetes.

Teine põhimõtteline otsus tundub puudutavat verbi võtma, mida tuleviku väljendamise võimalusena mainiti esmakordselt Anton Thor Helle grammatikas, mis esindas 1720.-1730. aastatel aktiivselt vaimulikke tekste välja andnud pietistlike pastorite pilti eesti keelest. Konstruktsiooni võtma $+d a$-infinitiiv kasutati varasemast märksa rohkem ka pietistide piibliredaktsioonides (UT 1729, P 1739), ehkki kvantitatiivselt polnud see muutus muidugi ligilähedaseltki võrreldav konstruktsioonist saama + infinitiiv loobumisega, vt tabelit järgmisel leheküljel.

$\mathrm{Ka}$ asjaolu, et mitmes grammatikas mainitakse tuleviku väljendajatena muu hulgas verbe tahtma ja pidama, kajastub tõlgetes, kus neid tegusõnu kasutatakse tõepoolest terve vaadeldud perioodi jooksul palju tulevikule viitamiseks. 
Tuleviku tulekust

Tabel. Tulevikulisuse vormistamine esimestes eestikeelsetes Luuka evangeeliumi tõlgetes

\begin{tabular}{|c|c|c|c|c|c|c|c|c|c|c|}
\hline $\begin{array}{l}\text { Piibli } \\
\text { tõlke- } \\
\text { versioon }\end{array}$ & 离 & 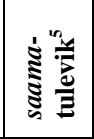 & 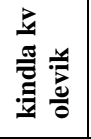 & 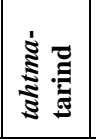 & 赵疍 & 疍造 & 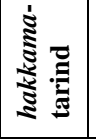 & 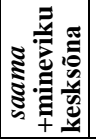 & 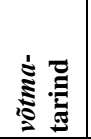 & $\Xi$ \\
\hline \begin{tabular}{|l} 
Müller \\
$1600-06$
\end{tabular} & \begin{tabular}{|l|}
4 \\
$(44,4 \%)$
\end{tabular} & & & & & & & & & \\
\hline \begin{tabular}{|l|} 
Rossihnius \\
1632
\end{tabular} & \begin{tabular}{|l|}
13 \\
$(1,00 \%)$
\end{tabular} & \begin{tabular}{|l|}
62 \\
$(4,76 \%)$ \\
\end{tabular} & \begin{tabular}{|l|}
6 \\
$(0,46 \%)$ \\
\end{tabular} & \begin{tabular}{|l|}
6 \\
$(0,46 \%)$ \\
\end{tabular} & & & & & & \\
\hline $\begin{array}{l}\text { Stahl } \\
\text { HHB } 1638\end{array}$ & \begin{tabular}{|l|}
13 \\
$(1,28 \%)$
\end{tabular} & \begin{tabular}{|l|}
54 \\
$(5,31 \%)$
\end{tabular} & \begin{tabular}{|l|}
6 \\
$(0,59 \%)$ \\
\end{tabular} & $\begin{array}{l}6 \\
(0,59 \%)\end{array}$ & & & & $\begin{array}{l}1 \\
(0,10 \%)\end{array}$ & & \\
\hline \begin{tabular}{|l|} 
Stahl LS \\
1641,49 \\
\end{tabular} & \begin{tabular}{|l|}
6 \\
$(1,03 \%)$
\end{tabular} & \begin{tabular}{|l|}
35 \\
$(6,03 \%)$ \\
\end{tabular} & \begin{tabular}{|l|}
4 \\
$(0,69 \%)$ \\
\end{tabular} & \begin{tabular}{|l|}
2 \\
$(0,34 \%)$ \\
\end{tabular} & & & & & & \\
\hline \begin{tabular}{|l|} 
Gutslaff \\
$1648 ?-56 ?$
\end{tabular} & \begin{tabular}{|l|}
32 \\
$(0,96 \%)$
\end{tabular} & $\begin{array}{l}201 \\
(6,05 \%)\end{array}$ & \begin{tabular}{|l|}
26 \\
$(0,78 \%)$
\end{tabular} & \begin{tabular}{|l|}
21 \\
$(0,63 \%)$
\end{tabular} & \begin{tabular}{|l|}
5 \\
$(0,15 \%)$
\end{tabular} & \begin{tabular}{|l|}
7 \\
$(0,21 \%)$
\end{tabular} & \begin{tabular}{|l|}
3 \\
$(0,09 \%)$
\end{tabular} & \begin{tabular}{|l|}
1 \\
$(0,03 \%)$
\end{tabular} & & $\begin{array}{l}9 \\
(0,27 \%)\end{array}$ \\
\hline EE 1673 & \begin{tabular}{|l|}
14 \\
$(1,26 \%)$ \\
\end{tabular} & \begin{tabular}{|l|}
59 \\
$(5,29 \%)$ \\
\end{tabular} & \begin{tabular}{|l|l|}
5 \\
$(0,45 \%)$ \\
\end{tabular} & \begin{tabular}{|l|}
6 \\
$(0,54 \%)$ \\
\end{tabular} & & & & \begin{tabular}{|l|}
1 \\
$(0,09 \%)$ \\
\end{tabular} & & \\
\hline \begin{tabular}{|l|} 
Pil must \\
$1680-87$ \\
\end{tabular} & \begin{tabular}{|l|}
56 \\
$(1,73 \%)$ \\
\end{tabular} & \begin{tabular}{|l|}
177 \\
$(5,46 \%)$ \\
\end{tabular} & \begin{tabular}{|l|}
66 \\
$(0,80 \%)$ \\
\end{tabular} & \begin{tabular}{|l|}
22 \\
$(0,68 \%)$
\end{tabular} & \begin{tabular}{|l|}
4 \\
$(0,12 \%)$ \\
\end{tabular} & \begin{tabular}{|l|}
1 \\
$(0,03 \%)$ \\
\end{tabular} & \begin{tabular}{|l|}
3 \\
$(0,09 \%)$ \\
\end{tabular} & \begin{tabular}{|l|}
1 \\
$(0,03 \%)$ \\
\end{tabular} & \begin{tabular}{l|}
1 \\
$(0,03 \%)$ \\
\end{tabular} & \begin{tabular}{|l|}
5 \\
$(0,15 \%)$ \\
\end{tabular} \\
\hline WT 1686 & \begin{tabular}{|l|}
44 \\
$(1,04 \%)$ \\
\end{tabular} & \begin{tabular}{|l|}
245 \\
$(5,79 \%)$ \\
\end{tabular} & \begin{tabular}{|l|}
1 \\
$(0,97 \%)$ \\
\end{tabular} & \begin{tabular}{|l|}
25 \\
$(0,59 \%)$ \\
\end{tabular} & \begin{tabular}{|l|l|}
11 \\
$(0,26 \%)$
\end{tabular} & \begin{tabular}{|l|}
7 \\
$(0,17 \%)$ \\
\end{tabular} & \begin{tabular}{|l|}
4 \\
$(0,09 \%)$ \\
\end{tabular} & & & \begin{tabular}{|l|}
10 \\
$(0,24 \%)$ \\
\end{tabular} \\
\hline $\begin{array}{l}\text { Pil puht } \\
1687\end{array}$ & \begin{tabular}{|l|}
79 \\
$(2,44 \%)$
\end{tabular} & \begin{tabular}{|l|}
167 \\
$(5,17 \%)$
\end{tabular} & \begin{tabular}{|l|}
28 \\
$(0,87 \%)$
\end{tabular} & & $\begin{array}{l}13 \\
(0,40 \%)\end{array}$ & \begin{tabular}{|l|}
4 \\
$(0,12 \%)$
\end{tabular} & \begin{tabular}{|l|}
3 \\
$(0,09 \%)$
\end{tabular} & & \begin{tabular}{l|}
1 \\
$(0,03 \%)$
\end{tabular} & $\begin{array}{l}4 \\
(0,12 \%)\end{array}$ \\
\hline EE 1693 & \begin{tabular}{|l|}
14 \\
$(1,26 \%)$
\end{tabular} & \begin{tabular}{|l|}
55 \\
$(4,94 \%)$
\end{tabular} & \begin{tabular}{|l|}
10 \\
$(0,90 \%)$ \\
\end{tabular} & \begin{tabular}{|l|}
6 \\
$(0,54 \%)$
\end{tabular} & & & & & & \\
\hline \begin{tabular}{|l} 
Münch \\
1694
\end{tabular} & \begin{tabular}{|l|}
194 \\
$(4,57 \%)$
\end{tabular} & & \begin{tabular}{|l|}
139 \\
$(3,28 \%)$ \\
\end{tabular} & \begin{tabular}{|l|}
28 \\
$(0,66 \%)$
\end{tabular} & \begin{tabular}{|l|}
2 \\
$(0,05 \%)$ \\
\end{tabular} & \begin{tabular}{|l|}
7 \\
$(0,17 \%)$ \\
\end{tabular} & \begin{tabular}{|l|}
5 \\
$(0,12 \%)$ \\
\end{tabular} & \begin{tabular}{|l|}
2 \\
$(0,05 \%)$ \\
\end{tabular} & \begin{tabular}{|l|l}
3 \\
$(0,07 \%)$
\end{tabular} & \begin{tabular}{|l|}
11 \\
$(0,26 \%)$ \\
\end{tabular} \\
\hline EE 1695 & \begin{tabular}{|l|}
43 \\
$(3,94 \%)$ \\
\end{tabular} & & \begin{tabular}{|l|l}
35 \\
$(3,21 \%)$ \\
\end{tabular} & \begin{tabular}{|l|}
3 \\
$(0,27 \%)$ \\
\end{tabular} & \begin{tabular}{|l|l|}
1 \\
$(0,09 \%)$
\end{tabular} & & & \begin{tabular}{|l|}
3 \\
$(0,27 \%)$ \\
\end{tabular} & & \\
\hline $\begin{array}{l}\text { Stock } \\
1705 \\
\end{array}$ & \begin{tabular}{|l|}
182 \\
$(4,27 \%)$
\end{tabular} & & \begin{tabular}{|l|l}
154 \\
$(3,61 \%)$ \\
\end{tabular} & \begin{tabular}{|l|}
29 \\
$(0,68 \%)$ \\
\end{tabular} & \begin{tabular}{|l|}
2 \\
$(0,05 \%)$ \\
\end{tabular} & \begin{tabular}{|l|}
7 \\
$(0,16 \%)$ \\
\end{tabular} & \begin{tabular}{|l|}
5 \\
$(0,12 \%)$ \\
\end{tabular} & \begin{tabular}{|l|}
6 \\
$(0,14 \%)$ \\
\end{tabular} & \begin{tabular}{|l|l}
3 \\
$(0,07 \%)$ \\
\end{tabular} & \begin{tabular}{|l|}
5 \\
$(0,12 \%)$ \\
\end{tabular} \\
\hline UT 1715 & \begin{tabular}{|l|}
185 \\
$(4,32 \%)$ \\
\end{tabular} & & \begin{tabular}{|l|}
149 \\
$(3,48 \%)$ \\
\end{tabular} & \begin{tabular}{|l|}
30 \\
$(0,70 \%)$ \\
\end{tabular} & \begin{tabular}{|l|}
4 \\
$(0,09 \%)$ \\
\end{tabular} & \begin{tabular}{|l|l}
6 \\
$(0,14 \%)$ \\
\end{tabular} & \begin{tabular}{|l|}
5 \\
$(0,12 \%)$ \\
\end{tabular} & \begin{tabular}{|l|}
8 \\
$(0,19 \%)$ \\
\end{tabular} & \begin{tabular}{|l|}
3 \\
$(0,07 \%)$ \\
\end{tabular} & \begin{tabular}{|l|}
3 \\
$(0,07 \%)$ \\
\end{tabular} \\
\hline EE 1727 & \begin{tabular}{|l|}
44 \\
$(3,96 \%)$ \\
\end{tabular} & & \begin{tabular}{|l|}
33 \\
$(2,97 \%)$ \\
\end{tabular} & \begin{tabular}{|l|}
4 \\
$(0,36 \%)$ \\
\end{tabular} & \begin{tabular}{|l|l|}
1 \\
$(0,09 \%)$ \\
\end{tabular} & & & \begin{tabular}{|l|}
1 \\
$(0,09 \%)$ \\
\end{tabular} & \begin{tabular}{l|l}
1 \\
$(0,09 \%)$ \\
\end{tabular} & \begin{tabular}{|l|}
1 \\
$(0,09 \%)$ \\
\end{tabular} \\
\hline UT 1729 & \begin{tabular}{|l|}
191 \\
$(4,41 \%)$ \\
\end{tabular} & & \begin{tabular}{|l|}
39 \\
$(3,21 \%)$ \\
\end{tabular} & \begin{tabular}{|l|}
77 \\
$(0,62 \%)$ \\
\end{tabular} & \begin{tabular}{|l|}
4 \\
$(0,09 \%)$ \\
\end{tabular} & \begin{tabular}{|l|}
6 \\
$(0,14 \%)$ \\
\end{tabular} & \begin{tabular}{|l|}
6 \\
$(0,14 \%)$ \\
\end{tabular} & \begin{tabular}{|l|}
6 \\
$(0,14 \%)$ \\
\end{tabular} & \begin{tabular}{|l|}
11 \\
$(0,25 \%)$
\end{tabular} & \begin{tabular}{|l|}
3 \\
$(0,07 \%)$ \\
\end{tabular} \\
\hline P 1739 & \begin{tabular}{|l|}
189 \\
$(4,37 \%)$ \\
\end{tabular} & & \begin{tabular}{|l|l}
140 \\
$(3,23 \%)$ \\
\end{tabular} & \begin{tabular}{|l|}
27 \\
$(0,62 \%)$ \\
\end{tabular} & \begin{tabular}{|l|}
5 \\
$(0,12 \%)$ \\
\end{tabular} & \begin{tabular}{|l|l}
6 \\
$(0,14 \%)$ \\
\end{tabular} & \begin{tabular}{|l|}
6 \\
$(0,14 \%)$ \\
\end{tabular} & \begin{tabular}{|l|}
6 \\
$(0,14 \%)$ \\
\end{tabular} & \begin{tabular}{|l|l}
10 \\
$(0,23 \%)$ \\
\end{tabular} & \begin{tabular}{|l|}
3 \\
$(0,07 \%)$ \\
\end{tabular} \\
\hline Kokku & 1303 & 1055 & 941 & 242 & 52 & 51 & 40 & 36 & 33 & 54 \\
\hline
\end{tabular}

${ }^{4}$ Siia hulka on loetud ka 95 tingivas kõneviisis pidama-konstruktsiooni ning 15 pidama-võima-konstruktsiooni.

${ }^{5}$ Siia hulka on loetud ka 13 saama-tulevikus hakkama-konstruktsiooni, 2 tahtma-konstruktsiooni ja 12 tingiva kõneviisi vormi. 


\section{Levinumad tulevikulisuse väljendusvahendid}

\section{Saama + infinitiiv}

Esimestes säilinud eestikeelsetes tekstikatketes 16. sajandist saa$m a$-tulevikku ei leidu (Mägiste 1936: 72), samuti ei kasutanud seda veel Georg Müller 17. sajandi esimesel kümnendil (Habicht 2001a: 170 ja Ross 1999: 12) ${ }^{6}$. Selle kõrgaeg kestis pisut üle poole sajandi, Rossihniuse ja Stahli kirikuraamatutest kuni Pilistvere puhtandkäsikirjani (k.a). 1739. aasta täispiiblis tuleb saama-futuurum ette haruharva (Mägiste 1936: 73 ja Ross 2006: 42). Saama-tulevikuga tõlgiti enamasti puhta ajatähendusega tulevikuvorme, nt Lk 21:11:

WT 1686: Nink suhre Mah Wärrisemisse sahwa ollema mitman Paigan / nink Nälg / nink Jummalawitz / nink Hirm / nink suhre Tähe Taiwast sahwa sündima.

(vrd Müller 1600-06: ninck piddab v̈x suhr Maa|werrisemene sÿn ninck sael sündima, ninck scel piddab ollema Katku ninck Kallis ä̈ck. Ninck scel piddawat suhret ninck hirmsat Im e e|aßiattcehet sündima)

(vrd Münch 1694: Ning suri Ma wärrisemissi peab ollema mitmes Paigas, ning Nälga ja katko peab ollema, ning hirm ja suri Tähtesid Taiwast peab ollema.)

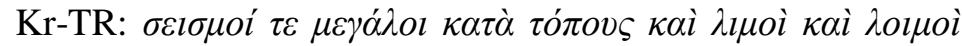

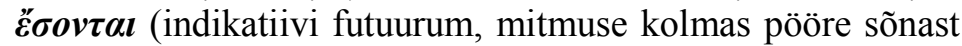

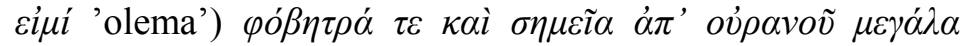

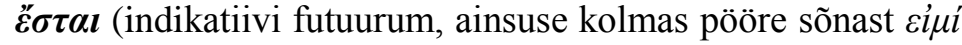
'olema')

Ld-V: terraemotus magni erunt (indikatiivi futuurum, mitmuse kolmas pööre sõnast sum 'olema') per loca et pestilentiae et fames terroresque de caelo et signa magna erunt (indikatiivi futuurum, mitmuse kolmas pööre sõnast sum 'olema')

\footnotetext{
${ }^{6}$ Sellest on ainult kaks eesti-saksa segakeelset näidet (Penjam 2008: 265-266). Küll aga esines Mülleri jutlusetekstides kaks korda ühend saama imperfektivorm + ma-tegevusnimi ja ligi viissada korda saama + tud-partitsiip (Prillop 2001: 185).
} 
Sks-L: und es werden geschehen (indikatiivi futuurum, mitmuse kolmas pööre sõnast geschehen 'juhtuma, toimuma') große Erdbeben hin und wieder, teure Zeit und Pestilenz; auch werden Schrecknisse und große Zeichen am Himmel geschehen (indikatiivi futuurum, mitmuse kolmas pööre sõnast geschehen 'juhtuma, toimuma').

\section{Pidama + infinitiiv}

Pidama on vana kirjakeele sagedasim modaalverb (Habicht 2001c: 166). Pille Penjami (2008: 261) arvutused näitavad, et pidama-konstruktsiooni esines Mülleri tekstides 6,5 korda ja Stahli tekstides 2 korda rohkem kui 20. sajandi kirjakeeles. Konstruktsiooni suurem populaarsus Mülleril on loomulik, sest ta kasutas seda saama-futuurumi asemel tulevikulisuse väljendamiseks. Hilisemates, 1630.-1680. aastate piiblitõlgetes tarvitatud pidama-tarindid kopeerisid enamjaolt sks-L sollen- ja müssen-konstruktsioone ehk teisisõnu nõrka ja tugevat kohustust väljendavaid modaalverbiühendeid, kus modaaltähendus pole tulevikutähendusest selgelt eristatav. Kr-TR-s ja ld-V-s oli neis kohtades samuti tarind 'pidama' + infinitiiv ( $\mathrm{kr} \delta \varepsilon \tilde{\varepsilon}, \tilde{\varepsilon} \chi \omega$ või $\mu \dot{\delta} \lambda \lambda \omega$, ld oportet ja necesse), konjunktiiv, indikatiivi futuurum, aga sageli ka hoopis midagi muud. Taas suurenes pidamatarindite sagedus hüppeliselt Müncheni käsikirjas, kus jäid äsja kirjeldatud eelkõige kohustust väljendavad pidama-tarindid samuti alles, kuid lisaks sai pidama juurde sisuliselt tuleviku abiverbi staatuse, sest sellega tõlgiti seal ja järgnevates piibliredaktsioonides ka rohkesti selliseid öeldisi, mis olid nii kreeka, ladina kui ka saksa keeles indikatiivi futuurumivormis, st lähtekeeles vähemasti grammatiliselt modaalsusvarjundita. Vrd nt Lk 1:33:

Münch 1694: Ning temma peab kunningas ollema Jakobi koja ülle iggawest, ning temma kunningrikkussel ei pea otsa ollema. (vrd EE 1693: nink temma sahp üx Kunningas olla ülle Jacobi Kodda iggawest / nink temma Kunniglik Rijhkkist ep sahp üx Oz olla.)

Kr-TR: $\kappa \alpha i ̀ ~ \beta \alpha \sigma l \lambda \varepsilon v ́ \sigma \varepsilon \boldsymbol{\imath}$ (indikatiivi futuurum, ainsuse kolmas

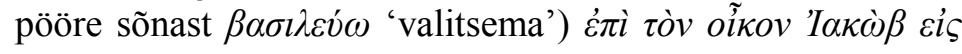




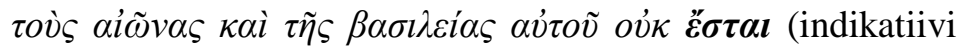

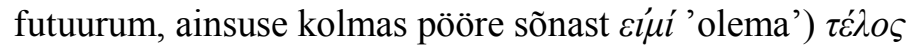

Ld-V: et regnabit (indikatiivi futuurum, ainsuse kolmas pööre sõnast regno 'valitsema') in domo Iacob in aeternum et regni eius non (eitussõna) erit (indikatiivi futuurum, ainsuse kolmas pööre sõnast sum 'olema') finis

Sks-L: und er wird ein König sein (indikatiivi futuurum, ainsuse kolmas pööre sõnast sein 'olema') über das Haus Jakob ewiglich, und seines Königreiches wird kein Ende sein (indikatiivi futuurum, ainsuse kolmas pööre sõnast sein 'olema').

Lisaks tuli Müncheni käsikirjas juurde ka palju mittetulevikulisi pidama-ühendeid, nt piiblisalmides Agga missuggusse Jssalt teie säast Poig Leiba küssib, ke temmale kiwwe peaks andma? Ning kui temma kalla pallub, ke temmale Maddo peaks andma kalla Assemelle? (Lk 11:11); Agga kui temma Rahwast kulis möda minnewa, küssi temma, mis se piddi ollema (Lk 18:36) ja Agga nemmad said hulluks, ning räksid teine teisega, mis nemmad se Jesulle piddid teggema (Lk 6:11). Kuna Müncheni käsikirjas ei laienenud pidama-verbi kasutusala mitte ainult tuleviku ja ettemääratuse, vaid ka muude tähenduste väljendajana, muutub arusaadavamaks, miks ei maininud Johann Hornung oma selleaegses grammatikas kõnealust tegusõna futuurumi asendusviiside nimekirjas.

\section{Tahtma + infinitiiv}

Teise vanas kirjakeeles sageda modaalverbi tahtma kasutus oli mõneti sarnane pidama-verbiga. Ka see oli Mülleri tekstides märksa populaarsem kui Stahlil (Penjam 2008: 215) ja samamoodi kui pidama-tarindite puhul leidus tulevikulisi tahtmatarindeid, mida kasutati kõigis vaadeldud perioodi tõlgetes. Püsima jäi tahtma tuleviku abiverbi staatus 20 öeldise tõlkimisel ehk umbes pooltel juhtudel neist 38 korrast, kui tuleviku tõlkimiseks tahtma-tarindit kasutati. Neis 20 kohas, kus kõik eesti tõlked kasutasid tahtma-konstruktsiooni, seisis Lutheri tõlkes wollen-konstruktsioon, kreeka ja ladina keeles enamasti indikatiivi futuurum, mõnel korral ka konstruktsioon 'tahtma' + infini- 
tiiv (kr $\beta o v ́ \lambda o \mu \alpha l$ või $\theta \varepsilon \dot{\lambda} \omega$, ld volo). Ülejäänud 18 öeldise tõlkimisel oli erinevusi, enamasti loobuti alates Müncheni käsikirjast tahtma-ühendist, nt Lk 1:66 tõlkimisel:

EE 1693: nink keik / ke sedda kuhlsit / wotsit sedda Süddamel I nink pajatasit: Mis motlet sa tahhap sest sinnasest Lapsokessest sahda? Sest se Issanda Kessi olli temma ka.

(vrd Münch 1694: Ning keig, kummad sedda kuulsid, pannid sedda süddamesse panna, ning üttlid: Mis sest Lapsest sa$\boldsymbol{n e b}^{7}$ ? Ning Jssanda kässi olli temmaga.)

(vrd EE 1727: Ja keik / kes sedda kuulsid / pannid sedda omma süddamesse / ja ütlesid: mis peab sest lapsest sama? ning Jssanda kässi olli temmaga.)

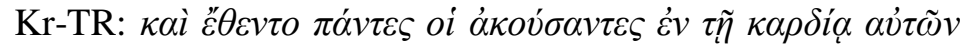

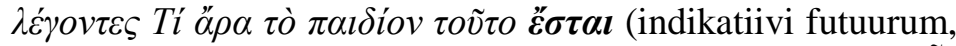

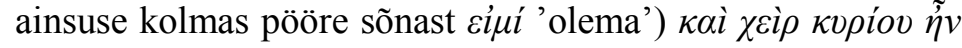
$\mu \varepsilon \tau^{\prime} \alpha \dot{v} \tau o \tilde{v}$

$\mathrm{Ld}-\mathrm{V}$ : et posuerunt omnes qui audierant in corde suo dicentes quid putas puer iste erit (indikatiivi futuurum, ainsuse kolmas pööre sõnast sõnast sum 'olema') etenim manus Domini erat cum illo

Sks-L: Und alle, die es hörten, nahmen's zu Herzen und sprachen: Was, meinst du, will (indikatiivi preesens, ainsuse kolmas pööre sõnast wollen 'tahtma') aus dem Kindlein werden (preesensi infinitiiv sõnast werden 'saama')? Denn die Hand des HERRN war mit ihm.

Leidus aga ka vastupidiseid juhtumeid, kus Müncheni käsikiri tõi tahtma-konstruktsioone juurde. Sinna lisandus kuus taht$m a$-tulevikku, mille paralleeliks on kõigis kolmes vaadeldud mõjukeeles futuurumivormid, ka saksa keeles werden-futuurum. Niisiis asus Müncheni käsikiri esmakordselt tahtma-ühenditega tõlkima ka selliseid kirjakohti, kus kolmes võimalikus lähtetekstis seisis modaalse lisavarjundita verbivorm, nt Lk 12:8:

\footnotetext{
${ }^{7}$ Potentsiaali kasutas ka WT 1686. Ülejäänud varastes Luuka evangeeliumi tõlkeversioonides (Rossihnius 1632, Stahl HHB 1638, EE 1673, Pil must 1680-87, Pil puht 1687, EE 1693) seisis tahtma-tarind.
} 
Münch 1694: ke eal mind üllestunnistab innimeste ees sedda tahhab ka innimesse Poig üllestunnistada Jummala Englide ees. (vrd Pil puht 1687: ke mund tunnistap Jnnimeste ees, tedda sahp kahß Jnnimeße poick tunnistama Jummala Englide ees.)

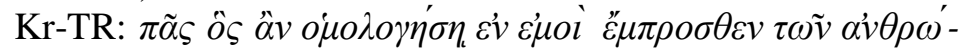

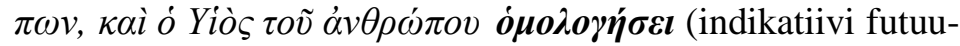
rum, ainsuse kolmas pööre sõnast $\dot{o} \mu o \lambda o \gamma \varepsilon \dot{\varepsilon} \omega$ 'tunnistama') $\dot{\varepsilon} v$

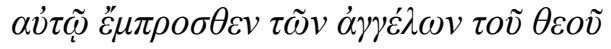

Ld-V: quicumque confessus fuerit in me coram hominibus et Filius hominis confitebitur (passiivi indikatiivi futuurum, ainsuse kolmas pööre sõnast confiteor 'tunnistama') in illo coram angelis Dei

Sks-L: Wer mich bekennet vor den Menschen, den wird auch des Menschen Sohn bekennen vor den Engeln Gottes. (indikatiivi futuurum, ainsuse kolmas pööre sõnast bekennen 'tunnistama')

\section{Hakkama + infinitiiv}

Tegevuse algust märkiva ühendiga hakkama/nakkama + infinitiiv tõlgiti konstruktsiooni 'algama, alustama' + infinitiiv, kus kreeka keeles seisis hakkama kohal verb ö $\rho \chi o \mu \alpha l$, ladina keeles incipio või coepio ning saksa keeles anfangen. Enne Müncheni käsikirja kasutati hakkama-tarindi asemel mõnikord ka algamatarindit, kõige rohkem Mülleri jutlustes (Penjam 2008: 269) ja Pilistvere mustandkäsikirjas. Et hakkama- ja algama-ühenditega kirjeldati enamasti minevikusündmusi, peeti tulevikust rääkides sageli vajalikuks panna need tulevikuvormi nii eeskujukeeltes kui ka saama-tulevikku sallivates eesti tõlgetes. Hakkama, mis tänapäeva eesti keeles tuleviku abiverbiks kujuneb (Metslang 1993: 205 ja 1994: 536, 606-609), tundub vanas kirjakeeles olevat märkinud veel üksnes algust (Penjam 2008: 289). Vt nt Lk 13:25:

Pil must 1680-87: sahte teiie halkma weljas seißada, kolkustada ninck ütleda

WT 1686: sahde teije nakkama ussen saisma / nink Usse pähle kopputama / nink ütlema 
Pil puht 1687: sahte teiie hakkama weljas seißama, Uxe pähle kolkustama ninck ütlema

(vrd Münch 1694: hakkate teie ukse ees oues saisma, ning ust kopputama, ütteldes)

Kr-TR: $\ddot{\alpha} \boldsymbol{\rho} \boldsymbol{\xi} \boldsymbol{\eta} \boldsymbol{\sigma} \boldsymbol{\varepsilon} \boldsymbol{\varepsilon}$ (konjunktiivi aorist, mitmuse teine pööre

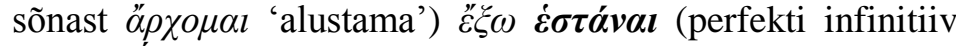

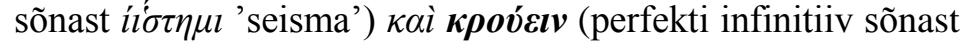
$\kappa \rho o v ́ \omega$ 'koputama') $\tau \grave{\eta} v \theta \dot{\rho} \rho \alpha \nu \lambda \dot{\varepsilon} \gamma o v \tau \varepsilon \varsigma$

Ld-V: incipietis (indikatiivi futuurum, mitmuse teine pööre sõnast incipio 'alustama') foris stare (preesensi infinitiiv sõnast sto 'seisma') et pulsare (preesensi infinitiiv sõnast pulso 'lööma') ostium dicentes

Sks-L: werdet ihr dann anfangen (indikatiivi futuurum, mitmuse teine pööre sõnast anfangen 'alustama') draußen $z u$ stehen (preesensi infinitiiv sõnast stehen 'seisma') und an die Tür klopfen (preesensi infinitiiv sõnast klopfen 'koputama') und sagen (preesensi infinitiiv sõnast sagen 'ütlema')

\section{Võtma $+d a$-infinitiiv}

Konstruktsiooni võtma $+d a$-infinitiiv kasutati samuti tegevuse alguse väljendamiseks nagu hakkama- ja algama-ühendeidki, kuid esimese tähendusnüansiks tundub olevat tegevuse otsustav ja sihipärane alustamine, nagu on täispiibli keelele iseloomulikke võtma-tarindeid analüüsides märkinud Kristiina Ross (2006: 43). Samamoodi kui hakkama- ja algama-tarindite puhul oli kreeka, ladina ja saksa tekstis vastaval kohal 'algama' + infinitiiv $^{8}$ ja konstruktsiooni võis kasutada ka minevikusündmustest jutustamiseks, näiteks üks Lk 4:21 öeldistest kõlab eri piibliredaktsioonides halgis ütleda, halgis ütlema, naksi ütlema, hakkas ütlema ja wottis üttelda. Kuni pietistide toimetatud tõlkeversioonideni (EE 1727, UT 1729, P 1739) kasutati võtma-ühendit

\footnotetext{
${ }^{8}$ Saksa keeles ühel korral (Lk 3:8) ka vornehmen + infinitiiv: Lutheri nehmt euch nicht vor, zu sagen tõlgib Pilistvere mustandkäsikiri wotket henneßel mitte ette ütleda, samamoodi ka kõik järgnevad tõlkeversioonid. Üksnes Wastne Testament kasutab seal nakkama-tarindit.
} 
kõige enam paaril korral, ${ }^{9}$ nemad aga lisasid Luuka evangeeliumi veel kümmekond tarvitusjuhtu, millega tõlgiti tulevikuvorme, nt Lk 20:15:

UT 1729: Mis wottab nü̈d se winamäe Issand neile tehha? (vrd WT 1686: Mes nühd se Wihna-Mäe Essand neile sahb teggema?)

(vrd Münch 1694: Mis peaks neile wina Mä Jssand tegge$m a ?)$

Kr-TR: $\tau i$ ỡv $\boldsymbol{\pi} \boldsymbol{0} \boldsymbol{\eta} \boldsymbol{\sigma} \boldsymbol{\sigma} \boldsymbol{\varepsilon}$ (indikatiivi futuurum, ainsuse kolmas

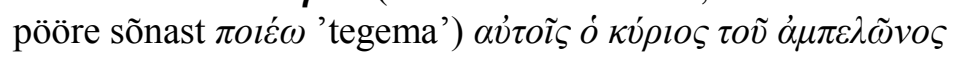
Ld-V: quid ergo faciet (indikatiivi futuurum, ainsuse kolmas pööre sõnast facio 'tegema') illis dominus vineae

Sks-L: Was wird nun der Herr des Weinberges ihnen tun? (indikatiivi futuurum, ainsuse kolmas pööre sõnast tun 'tegema')

\section{Saama + mineviku kesksõna}

Konstruktsioon saama + mineviku kesksõna on üks 1739. a täispiibli keele iseloomulikke jooni (Mägiste 1936: 73 ja Ross 2006: 39). Sellega rõhutatakse tegevuse perfektiivsust ja väljendatakse tavaliselt suhtelist tulevikku, aga mõnikord ka minevikku, nt sai teinud (Ross 2006: 40-41). Luuka evangeeliumi tõlkeloos kasvab selle konstruktsiooni sagedus tasapisi Müncheni käsikirjast alates: Münch 1694 tõlgib sellega kaks öeldist, selle redigeeritud versioon Stockholmi käsikiri (Stock 1705) neli ning järgnenud Uue Testamendi trükiversioonid (UT 1715, UT 1729, P 1739) kuus öeldist. Enne Müncheni käsikirja kasutati kõnealust konstruktsiooni mõnes tõlkeversioonis ühe öeldise puhul (Lk 16:4 saan ära heidetud). Seejuures pole märgata üht kindlat kr-TR, ld-V ega sks-L keelendit, mida eesti tõlgetes leiduvate ühendite-

${ }^{9}$ Kuna tegemist on üsna harva konstruktsiooniga, ei saa ainult minu analüüsitud tekstide põhjal otsustada, kas võtma $+d a$-infinitiiv tegelikult ka nendes tekstides täiesti puudub, kus seda Luuka evangeeliumis ei leidunud. Näiteks esineb seda Luuka evangeeliumis puudumisest hoolimata Stahli perikoopides neli korda ja jutluseraamatus üks kord (Habicht 2001b: 262). 
ga eestindataks. Konstruktsiooni saama + mineviku kesksõna kohal seisavad Kr-TR tekstis enamjaolt subjunktiivi aorist või indikatiivi futuurum, ld- $\mathrm{V}$ tekstis kõige sagedamini indikatiivi teine futuurum ja sks-L tekstis indikatiivi perfekt või futuurum. Nende kirjakohtade teistsugustest eestindustest on levinuimad indikatiivi perfekt ning saama-futuurum, millest kumbki keskendub ühele konstruktsiooni peamistest tähendustest: esimene tegevuse lõpetatusele ja teine tulevikulisusele, vt nt Lk 18:33:

Münch 1694: Ning kui nemmad tedda Sawad peksnud, siis peawad nemmad tedda ärratapma, ning kolmandal päwal peab temma üllestousma.

(vrd WT 1686: Nink kui nemmä teddä omma pesnu / sis sahwa nemmä teddä errätapma: Nink kolmandel Peiwäl sahb temmä jälle üllestausma.)

(vrd EE 1693: nink nemmat sahwat tedda pexma / nink tapma / nink kolmandal Pähwal sahp temma jelle üllestausma.)

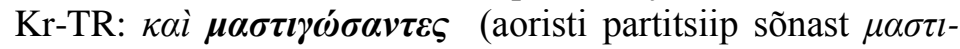

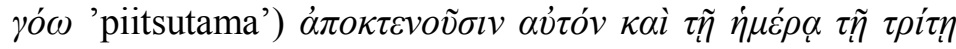
$\dot{\alpha} v \alpha \sigma \tau \dot{\sigma} \sigma \varepsilon \tau \alpha l$

Ld-V: et postquam flagellaverint (indikatiivi teine futuurum, mitmuse kolmas pööre sõnast flagello 'piitsutama') occident eum et die tertia resurget

Sks-L: und sie werden ihn geißeln (indikatiivi futuurum, mitmuse kolmas pööre sõnast geißeln 'piitsutama') und töten; und am dritten Tage wird er wieder auferstehen.

\section{Kokkuvõtteks}

Tulevikulisuse väljendamise suhtes tehti eesti kirjakeele algusaegadel põhimõtteliselt erinevaid otsuseid, sest tõlkimist vajavaid tulevikuvorme oli palju ning üht selgelt parimat moodust nende eestindamiseks mitte. Kuna keel vajab neutraalse tähendusega puhast tulevikutarindit (Metslang 1994: 604), pole imestada, et 1630.-1680. aastate piibliversioonides tulevikusündmusi peamiselt just saama-futuurumiga edasi anti. Mõistetav on ka see, miks Johann Hornung 17. sajandi lõpul oma tõlkest selle 
konstruktsiooni välja jättis: hoolimata rahvakeelsest taustast oli massiline saksaeeskujuline kasutus (Mägiste 1936: 91) siiski liiga võõras.

Saama-futuurumi asemele toodud pidama-tarindite ja olevikuvormide puudusena võib omakorda nimetada tulevikutähenduse tagaplaanile jäämist. Oleviku kasutusala on liiga lai (Metslang 1994: 535). Pidama puhul on omakorda tajutav algne kohustuslikkuse leksikaaltähendus, mistõttu tundub pidama-tarindiga ka paljude lähtekeeles modaalvarjundita öeldiste tõlkimine alates 17. sajandi lõpust võrreldav varasema saama-konstruktsiooniga liialdamisega. Mitte ainult pidama-, vaid ka tahtma-, hakkama-, algama- ja võtma-konstruktsioonil on olemas lisatähendused, mis aitasid küll ilusti tuleviku väljendamist nüansseerida, kuid polnud vähemasti 17.-18. sajandi eesti kirjakeeles piisavalt tuhmunud, et võimaldada üldise tuleviku abiverbi staatust.

\author{
Annika Kilgi \\ Eesti keele ja kultuuri instituut \\ Tallinna Ülikool \\ Narva mnt 25 \\ 10120 Tallinn \\ Annika.Kilgi@tlu.ee
}

\title{
Kirjandus
}

Dahl, Östen (1985) Tense and aspect systems. Oxford: Blackwell.

Göseken, Heinrich (1660) Manuductio ad Linguam Oesthonicam. Reval: Adolph Simon. [Faksiimileväljaanne: Göseken, Heinrich (1977) Manuductio ad linguam Oesthonicam = Anführung zur Öhstnischen Sprache. Kommentiert und herausgegeben von Harald Haarmann. Hamburg: Helmut Buske.]

Gutslaff, Johannes (1648) OBSERVATIONES GRAMMATICAE circa linguam ESTHONICAM. Dorpat: Johannes Vogel. [Faksiimileväljaanne: Gutslaff, Johannes (1998) Observationes Grammaticae circa linguam Esthonicam. Grammatilisi vaatlusi eesti keelest. 
Toim. Marju Lepajõe, Jaak Peebo. (Tartu Ülikooli eesti keele õppetooli toimetised 10.) Tartu.]

Gutsleff, Eberhard (1732) "Vorrede". Thor Helle, Anton. Kurtzgefaßte Anweisung Zur Ehstnischen Sprache, 13-36. Halle: Stephan Orban. [Faksiimileväljaanne: Lühike sissejuhatus eesti keelde (2006). Tõlkinud ja järelsõnad kirjutanud Annika Kilgi ja Kristiina Ross. Tallinn: Eesti Keele Sihtasutus, Eesti Keele Instituut.]

Habicht, Külli (2001a) Eesti vanema kirjakeele leksikaalsest ja morfosüntaktilisest arengust ning Heinrich Stahli keele eripärast selle taustal. (Dissertationes philologiae estonicae universitatis tartuensis 10.) Tartu: Tartu Ülikooli Kirjastus.

Habicht, Külli (2001b) "Infinite Konstruktionen in der estnischen Schriftsprache der ersten Hälfte des 17. Jahrhunderts". Linguistica Uralica XXXVII, 4, 245-269.

Habicht, Külli (2001c) "Vanhan kirjaviron modaalirakenteista". Congressus Nonus Internationalis Fenno-Ugristarum 7.-13. 8. 2000. Pars IV. Dissertationes sectionum: Linguistica I, 268-276. Tartu.

Hennoste, Tiit (1997) „Eesti keele sotsioperioodid. Üldpilt“. Mati Erelt, Meeli Sedrik, Ellen Uuspõld, toim. Pühendusteos Huno Rätsepale 28.12.1997, 45-66. (Tartu Ülikooli eesti keele õppetooli toimetised 7.) Tartu: Tartu Ülikooli Kirjastus.

Hornung, Johann (1693) Grammatica Esthonica, brevi, Perspicua tamen methodo ad Dialectum Revaliensem. Riga: Joh. Georg Wilck. [Faksiimileväljaanne: Hornung, Johann (1977) Grammatica Esthonica, brevi, perspicua tamen methodo ad dialectum Revaliensem. Eingeleitet und herausgegeben von Harald Haarmann. Hamburg: Helmut Buske.]

Metslang, Helle (1993) „Verbitarind ajatähendust väljendamas“. Virittäjä 97, 2, 203-221.

Metslang, Helle (1994) „Eesti ja soome - futuurumita keeled?“. Keel ja Kirjandus 37, 9, 534-547, 10, 603-616.

Mägiste, Julius (1936) „Eesti saama-futuuri algupärast ja tarvitamiskõlblikkusest". Eesti Keel 3, 65-92.

Penjam, Pille (2008) Eesti kirjakeele da- ja ma-infinitiiviga konstruktsioonid. (Dissertationes philologiae estonicae universitatis tartuensis 23.) Tartu: Tartu Ülikooli Kirjastus.

Prillop, Külli (2001) Georg Mülleri jutluste verbivormistik. Käsikirjaline magistritöö. Tartu: Tartu Ülikool. Eesti keele õppetool.

Reila, Heiki (2007) „Müncheni käsikirjast ja selle seostest Johann Hornungi tõlkega: keelelisi tähelepanekuid“. Heiki Reila, Kristiina Ross, Kai Tafenau, toim., Kristiina Ross, koost. Põhjaeestikeelsed 
Uue Testamendi tõlked 1680-1705. Luuka evangeelium. Apostlite teod, 556-563. Tallinn: Eesti Keele Sihtasutus.

Ross, Kristiina (1999) „Kas eesti kirjakeel võinuks kujuneda teistsuguseks“. Mis on see ISE: tekst, tagapõhi, isikupära, 9-30. Tallinn: Eesti Teaduste Akadeemia Underi ja Tuglase Kirjanduskeskus.

Ross, Kristiina (2006) „,,Lühike sissejuhatus“ ja eesti piiblitõlge“. Lühike sissejuhatus eesti keelde 1732, C26-C53. Tallinn: Eesti Keele Sihtasutus.

Stahl, Heinrich (1637) Anführung zu der Esthnischen Sprach, auff Volgemeinten Rath, und Bittliches Ersuchen. Revall: Chr. Reusner. [Faksiimileväljaanne: Stahl, Heinrich (2000) Anführung zu der Estnischen Sprach auff wolgemeinten Rath und bittliches Ersuchen. 2nd print. Tartu: Johannes Esto Ühing.]

Tafenau, Kai (2006) „Eestikeelsetest Uue Testamendi tõlkekäsikirjadest Ajalooarhiivis“. Koost. Enn Küng. Läänemere provintside arenguperspektiivid Rootsi suurriigis 16/17. sajandil II, 241-294. (Eesti Ajalooarhiivi toimetised 12.) Tartu: Eesti Ajalooarhiiv.

Tafenau, Kai (2010) „Heinrich Gösekeni käsikirja kohast 17. sajandi eesti piiblitõlke traditsioonis“. Emakeele Seltsi aastaraamat 55 (2009), 176-200. Tallinn: Teaduste Akadeemia kirjastus.

Thor Helle, Anton (1732) Kurtzgefaßte Anweisung Zur Ehstnischen Sprache. Halle: Stephan Orban. [Faksiimileväljaanne: Lühike sissejuhatus eesti keelde (2006) Tõlkinud ja järelsõnad kirjutanud Annika Kilgi ja Kristiina Ross. Tallinn: Eesti Keele Sihtasutus, Eesti Keele Instituut.]

WALS $2005=$ The world atlas of language structures. Martin Haspelmath, Matthew S. Dryer, David Gil, Bernard Comrie, toim. Oxford: Oxford University Press.

\section{Allikad}

EE 1673 = Di gewöhnliche Evangelia und Episteln (1673). Reval: Adolph Simon.

EE 1693 = Nehd pöhat Evangeliumit nink Epistlit keike Ahsta lebbi, Mah Kehle sehs kirjotut (1693). Tal-Linnas: Christoff Brendeken.

EE 1695 = Ewangeliumme ning Epistli-Loud (1695). Riga: Johann Georg Wilcken.

EE 1727 = Keik Ewangeliummid ning Epistlid keige se Aasta läbbi (1727). Tallinn: Joan Köler.

Gutslaff 1648?-1656? = Johannes Gutslaffi käsikirjalised jutlused.

Müller 1600-1606 = Georg Mülleri käsikirjalised jutlused. 
Münch 1694 = Põhjaeestikeelsed Uue Testamendi tõlked 1680-1705. Tallinn: Eesti Keele Sihtasutus, 2007.

P 1739 = Piibli Ramat (1739). Tallinn: Jakob Joan Köler. [Faksiimileväljaanne: Piibliraamat. Tallinn: Eesti Raamat, 1990.]

Pil must 1680-87 = Põhjaeestikeelsed Uue Testamendi tõlked 16801705. Tallinn: Eesti Keele Sihtasutus, 2007.

Pil puht 1687 = Põhjaeestikeelsed Uue Testamendi tõlked 1680-1705. Tallinn: Eesti Keele Sihtasutus, 2007.

Rossihnius 1632 = Rossihnius, Joachim (1632) Evangelia und Episteln auff alle Sontage durchs gantze Jahr. Riga: Gerhard Schröder. [Eesti piiblitõlke ajalooline konkordants. <http://www.eki.ee /piibel>. Vaadatud 30.06.2009.]

Stahl HHB 1638 = Stahl, Heinrich (1638) Hand- und Hauszbuch Für die Pfarherren und Hausz-Väter Esthnischen Fürstenthumbs. Dritter Theil. Revall: Christoff Reusner. [Eesti piiblitõlke ajalooline konkordants. 〈http://www.eki.ee/piibel>. Vaadatud 30.06.2009.]

Stahl LS 1641, 49 = Stahl, Heinrich (1641) Leyen Spiegel. Winter Theil. Reval: Heinrich Westphal; Stahl, Heinrich (1649) Leyen Spiegel. Sommer-Theil. Reval: Heinrich Westphal. [Vana kirjakeele korpus. <http://www.murre.ut.ee/vakkur/Korpused/korpused.htm>. Vaadatud 30.06.2009.]

Stock 1705 = Põhjaeestikeelsed Uue Testamendi tõlked 1680-1705. Tallinn: Eesti Keele Sihtasutus, 2007.

UT $1715=$ Meie Issanda Jesusse Kristusse Uus Testament Ehk Jummala Ue Sädusse Sanna. 1715. Tallinn: Johan Kristow Prendeken. [Faksiimileväljaanne: Uus Testament 1715. Tallinn: Eesti Rahvusraamatukogu, 2004.]

UT 1729 = Meie Issanda JESUSSE KRISTUSSE uus Testament ehk Ue Seädusse Ramat. ? 1729. Tallinn: Joan Köler.

WT 1686 = Meije Issanda Jesusse Kristusse Wastne Testament. 1686. Riga: Johann Georg Wilcken. [Faksiimileväljaanne: Wastne Testament 1686. Tallinn: Eesti Keele Sihtasutus, 2001.] 
Lisa 1. Vaadeldud Uue Testamendi tõlkeversioonid

\begin{tabular}{|c|c|c|c|}
\hline Lühend & Selgitus & $\begin{array}{l}\text { Öeldiste arv kõigis } \\
\text { Luuka evangee- } \\
\text { liumi katkendites }\end{array}$ & $\begin{array}{l}\text { Öeldiste arv, mida } \\
\text { kasutati tõlkimaks } \\
\text { kr-TR, ld-V või/ja } \\
\text { sks-L tulevikuvormi }\end{array}$ \\
\hline $\begin{array}{l}\text { Müller } \\
1600-06\end{array}$ & $\begin{array}{l}\text { Luuka evangeeliumi tsitaadid } \\
\text { Georg Mülleri käsikirjalistes } \\
\text { jutlustes }\end{array}$ & 9 & 4 \\
\hline $\begin{array}{l}\text { Rossihnius } \\
1632\end{array}$ & $\begin{array}{l}\text { Jutluse aluseks olevad Luuka } \\
\text { evangeeliumi katkendid } \\
\text { Joachim Rossihniuse lõuna- } \\
\text { eestikeelses kirikukäsiraama- } \\
\text { tus „Evangelia und Episteln } \\
\text { auff alle Sontage durchs } \\
\text { gantze Jahr“ }\end{array}$ & 1302 & 87 \\
\hline $\begin{array}{l}\text { Stahl HHB } \\
1638\end{array}$ & $\begin{array}{l}\text { Jutluse aluseks olevad Luuka } \\
\text { evangeeliumi katkendid } \\
\text { Heinrich Stahli kirikukäsi- } \\
\text { raamatus „Hand- und } \\
\text { Hauszbuch Für die } \\
\text { Pfarherren und Hausz-Väter } \\
\text { Esthnischen Fürstenthumbs“ }\end{array}$ & 1016 & 80 \\
\hline $\begin{array}{l}\text { Stahl LS } \\
1641,49\end{array}$ & $\begin{array}{l}\text { Luuka evangeeliumi tsitaadid } \\
\text { Heinrich Stahli jutluseraama- } \\
\text { tus „Leyen Spiegel““ }\end{array}$ & 580 & 47 \\
\hline $\begin{array}{l}\text { Gutslaff } \\
1648 ?-56 ?\end{array}$ & $\begin{array}{l}\text { Johannes Gutslaffi käsikirja- } \\
\text { line lõunaeestikeelne Uue } \\
\text { Testamendi tõlge }\end{array}$ & 3322 & 305 \\
\hline EE 1673 & $\begin{array}{l}\text { Jutluse aluseks olevad Luuka } \\
\text { evangeeliumi katkendid } \\
\text { kirikukäsiraamatus ,Di } \\
\text { gewöhnliche Evangelia und } \\
\text { Episteln“, mis on Stahli } \\
\text { perikoobiraamatu kolmas } \\
\text { trükk }\end{array}$ & 1115 & 85 \\
\hline $\begin{array}{l}\text { Pil must } \\
1680-87\end{array}$ & $\begin{array}{l}\text { Uue Testamendi tõlkekäsi- } \\
\text { kirjad, mille kallal töötati } \\
\text { 1687. aastal Pilistvere piibli- } \\
\text { konverentsil }\end{array}$ & 3240 & 296 \\
\hline WT 1686 & $\begin{array}{l}\text { Esimest korda trükist ilmu- } \\
\text { nud lounaeestikeelne Uus } \\
\text { Testament }\end{array}$ & 4233 & 387 \\
\hline $\begin{array}{l}\text { Pil puht } \\
1687\end{array}$ & $\begin{array}{l}\text { Pilistvere piiblikonverentsil } \\
\text { toimetatud käsikirja lõplik } \\
\text { kuju }\end{array}$ & 3233 & 299 \\
\hline
\end{tabular}


Tuleviku tulekust

\begin{tabular}{|c|c|c|c|}
\hline Lühend & Selgitus & $\begin{array}{l}\text { Öeldiste arv kõigis } \\
\text { Luuka evangee- } \\
\text { liumi katkendites }\end{array}$ & $\begin{array}{l}\text { Öeldiste arv, mida } \\
\text { kasutati tõlkimaks } \\
\text { kr-TR, ld-V või/ja } \\
\text { sks-L tulevikuvormi }\end{array}$ \\
\hline EE 1693 & $\begin{array}{l}\text { Jutluse aluseks olevad Luuka } \\
\text { evangeeliumi katkendid } \\
\text { kirikukäsiraamatus ,Nehd } \\
\text { pöhat Evangeliumit nink } \\
\text { Epistlit keike Ahsta lebbi, } \\
\text { Mah Kehle sehs kirjotut““, } \\
\text { mis on Stahli } \\
\text { perikoobiraamatu neljas } \\
\text { trükk }\end{array}$ & 1114 & 85 \\
\hline $\begin{array}{l}\text { Münch } \\
1694\end{array}$ & $\begin{array}{l}\text { Arvatavasti ümberkirjutus } \\
\text { Johann Hornungi tõlkever- } \\
\text { sioonist, mille ta koostas } \\
\text { 1687.-1688. a vahetult pärast } \\
\text { Pilistvere piiblikonverentsi }\end{array}$ & 4242 & 391 \\
\hline EE 1695 & $\begin{array}{l}\text { Jutluse aluseks olevad Luuka } \\
\text { evangeeliumi katkendid } \\
\text { kirikukäsiraamatus } \\
\text { „Ewangeliumme ning Epist- } \\
\text { li-Loud“, mida on keeleliselt } \\
\text { ja tõlkeliselt uuendanud } \\
\text { Adrian Virginius, Johann } \\
\text { Hornung jt }\end{array}$ & 1092 & 85 \\
\hline $\begin{array}{l}\text { Stock } \\
1705\end{array}$ & $\begin{array}{l}\text { Käsikiri, mis valmis Põhjasõ- } \\
\text { ja ajal Tallinnas Hornungi } \\
\text { tõlkeversiooni üheskoos } \\
\text { toimetades }\end{array}$ & 4266 & 393 \\
\hline UT 1715 & $\begin{array}{l}\text { Esimest korda trükist ilmu- } \\
\text { nud põhjaeestikeelne Uus } \\
\text { Testament }\end{array}$ & 4285 & 393 \\
\hline EE 1727 & $\begin{array}{l}\text { Jutluse aluseks olevad Luuka } \\
\text { evangeeliumi katkendid } \\
\text { kirikukäsiraamatus „Keik } \\
\text { Ewangeliummid ning Epist- } \\
\text { lid keige se Aasta läbbi““, } \\
\text { mida uustrüki jaoks põhjali- } \\
\text { kult parandasid Anton Thor } \\
\text { Helle, Heinrich Gutsleff jt }\end{array}$ & 1110 & 85 \\
\hline UT 1729 & $\begin{array}{l}\text { Põhjaeestikeelse Uue Testa- } \\
\text { mendi teine, põhjalikult } \\
\text { redigeeritud trükk }\end{array}$ & 4332 & 393 \\
\hline P 1739 & $\begin{array}{l}\text { Uus Testament esimeses } \\
\text { eestikeelses täispiiblis }\end{array}$ & 4328 & 392 \\
\hline
\end{tabular}


Annika Kilgi. The Arrival of Future: Expressing Futurity in the First Bible Translations in Estonian. The first translators of the Bible into Estonian had to decide how to mediate the many future forms of the source text despite the lack of inflectional future in Estonian. Fundamentally different decisions were made in this regard during the process of translating the first full Bible. At the beginning of $17^{\text {th }}$ century, Georg Müller did not use the saama-future. On the contrary, the Bible versions from the decades 1630-1680 used mainly this form for expressing futurity on the example of the German werden-future. At the end of the $17^{\text {th }}$ century, since the München manuscript, saamafuture was again completely abandoned and, instead, pidama-constructions and present indicative forms were used much more frequently than in previous translations. Another noticeable and fundamental change is the increased usage of the construction võtma + infinitive in the editions revised by pietists who gave the final touch to the language of the full Bible during the decades 1720-1730. However, no translator managed to find a neutral pure future construction. The abundance of saama-future was foreign and, on the other hand, the remaining possibilities (e.g. pidama-, tahtma-, hakkama-, algama-, and võtma-constructions) had other uses besides expressing futurity. The decision to translate the many future forms that had nothing to do with obligation by using the pidama-constructions is comparable with the earlier exaggeration of saama-constructions.

Keywords: expressing futurity, inflectional future, saama-construction, pidama-construction, history of Estonian Bible translation, gospel of Luke, $17^{\text {th }}$ century, $18^{\text {th }}$ century 